\title{
Effect of a-tocopheryloxy acetic acid on the infection of mice with Plasmodium berghei ANKA in vivo and humans with P. falciparum in vitro
}

\section{Nanang R Ariefta}

Obihiro University of Agriculture and Veterinary Medicine: Obihiro Chikusan Daigaku

\section{Aiko Kume}

Obihiro University of Agriculture and Veterinary Medicine: Obihiro Chikusan Daigaku

\section{Yoshifumi Nishikawa}

Obihiro University of Agriculture and Veterinary Medicine: Obihiro Chikusan Daigaku

\section{Tomoyo Taniguchi}

Obihiro University of Agriculture and Veterinary Medicine: Obihiro Chikusan Daigaku

\section{Rika Umemiya-Shirafuji}

Obihiro University of Agriculture and Veterinary Medicine: Obihiro Chikusan Daigaku

\section{Shunji Kasai}

Obihiro University of Agriculture and Veterinary Medicine: Obihiro Chikusan Daigaku

Hiroshi Suzuki ( $\nabla$ hisuzuki@obihiro.ac.jp )

National Research Center for Protozoan Diseases, Obihiro University of Agriculture and Veterinary

Medicine https://orcid.org/0000-0002-2638-0879

\section{Research Article}

Keywords: a-tocopheryloxy acetic acid, Mice, Red blood cell, Plasmodium falciparum, Plasmodium berghei, Reactive oxygen species

Posted Date: February 15th, 2022

DOI: https://doi.org/10.21203/rs.3.rs-1297424/v1

License: (c) (i) This work is licensed under a Creative Commons Attribution 4.0 International License. Read Full License 


\section{Abstract}

\section{Background}

Malarial parasites are susceptible to oxidative stress. The effects of a-tocopheryloxy acetic acid (a-TEA), a vitamin E analog, on infection by Plasmodium berghei ANKA and $P$. falciparum in mice and human red blood cells (RBCs), respectively, were examined in this study.

\section{Methods}

For in vivo studies in mice, RBCs infected with $P$. berghei ANKA were inoculated via intraperitoneal injection and a-TEA was administered to C57BL/6J male mice after infection. The blood-brain barrier (BBB) permeability was examined by Evans blue staining in experimental cerebral malaria at 7 days after infection. The in vitro inhibitory effect of a-TEA on $P$. falciparum 3D7 (chloroquine-sensitive strain) and K1 (multidrug-resistant strain) was tested using a SYBR Green I-based assay.

\section{Results}

When $1.5 \%$ a-TEA was administered for 14 days after infection, $88 \%$ of $P$. berghei ANKA-infected mice survived during the experimental period. Nevertheless, all the control mice died within 12 days of infection. Furthermore, the Evans blue intensity in a-TEA-treated mice brains was less than that in untreated mice, indicating that a-TEA might inhibit the destruction of the BBB and progression of cerebral malaria. The in vitro experiment revealed that a-TEA inhibited the proliferation of both the 3D7 and K1 strains.

\section{Conclusions}

This study showed that a-TEA is effective against murine and human malaria in vivo and in vitro, respectively. Although a-TEA alone has a sufficient antimalarial effect, future research could focus on the combined effect of a-TEA and already existing drugs. The prophylactic antimalarial activity of premedication with a-TEA may also be an interesting perspective in the future.

\section{Background}

It is well known that malaria parasites are sensitive to oxidative stress, since reactive oxygen species (ROS) lead to the hemolysis of host erythrocytes and parasite death [1, 2]. One vitamin E derivative, atocopheryl succinate (a-TOS), which is synthesized by esterification of a-tocopherol, leads to the production of ROS and exhibits anticancer activity in mice [3-6]. Previous studies have demonstrated that a-TOS inhibits mitochondrial complex II, resulting in the generation of ROS, which triggers selective apoptosis in malignant cells, while it appears to be non-toxic to normal cells [7-15]. In addition, cells lacking mitochondrial respiratory chain activity are not sensitive to a-TOS toxicity [10-13]. In murine malaria infection, administration of a-TOS after infection with Plasmodium yoelii 17XL or $P$. berghei ANKA resulted in a significant increase in host survival [16]. However, because a-TOS is decomposed by 
an esterase, its low stability and clinical application is challenging. Recently, significant effects of atocopheryloxy acetic acid (a-TEA), a stable vitamin E derivative [17], on P. yoelii 17XL infection have been reported in mice [18]. The a-TEA compound has an ether bond and is not degraded by esterase, making it suitable for oral administration $[19,20]$. Alpha-TEA stimulates mitochondria to generate ROS and induces apoptosis in tumor cells [21-24], while also enhancing the anti-tumor activity of trastuzumab against breast cancer $[25,26]$. Since a-TEA has a more pronounced inhibitory effect on breast cancer than a-TOS and is more stable in plasma [17], it was predicted that the stimulatory effect of a-TEA on mitochondria [27] and the associated responses, such as ROS generation, apoptosis induction, and autophagy stimulation [22], could have some effect on malaria infection [18].

In this study, to determine whether a-TEA is an appropriate anti-malarial drug candidate, C57BL/6J male mice were infected with $P$. berghei ANKA, a lethal strain of murine malaria and experimental cerebral malaria, and treated with a-TEA. In addition, to analyze whether the antiprotozoal effects were the result of modification of the physiology of the host or a direct effect on the protozoan, the effect of a-TEA on the growth of $P$. falciparum in vitro was also examined.

\section{Methods}

Experimental infection with $P$. berghei ANKA was carried out using C57BL/6J male mice (Japan CLEA, Tokyo, Japan) at biosafety level 2 in a specific pathogen-free facility. The room temperature $\left(24 \pm 1^{\circ} \mathrm{C}\right)$ and humidity (50 $\pm 10 \%$ ) were adjusted, and the lighting was controlled (lights on from 7 AM to 7 PM). The mice were allowed free access to water and a diet (CA-1; CLEA Japan, Tokyo, Japan). The animals used in this study were handled and cared for in accordance with the "Guiding Principles for the Care and Use of Research Animals" established by Obihiro University of Agriculture and Veterinary Medicine, Japan. All animal experimental procedures were approved by the Obihiro University of Agriculture and Veterinary Medicine Institutional Animal Ethics Committee (ethical approval number \#29-86, April 14, 2017; \#18-112, May 16, 2018; \#19-130, May 23, 2019).

Alpha-TEA (molecular weight $488.75 \mathrm{~g} / \mathrm{mol}$ ) distributed by Eisai (Eisai Co., Ltd., Tokyo, Japan) was mixed with the diet [0.75\% and $1.5 \%(\mathrm{w} / \mathrm{w})$ of a-TEA] and fed to 8-weeks old C57BL/6J male mice $(23-25 \mathrm{~g}$ body weight) for 14 days after infection. The day of infection was defined as Day 0 . The mixed diet was outsourced to Oriental Yeast Co. Ltd. (Tokyo, Japan).

For parasite infection, $4 \times 10^{4} \mathrm{P}$. berghei ANKA-infected red blood cells (iRBCs) were intraperitoneally injected into mice and their survival rates and parasitemia were monitored. On day 4 post-infection, $2 \mu \mathrm{L}$ of blood was collected from the tip of the tail, smeared on a glass slide, and stained with Giemsa (SigmaAldrich, Tokyo, Japan). The percentage of infected erythrocytes to total erythrocytes (parasitemia) was determined using a phase contrast microscope (DIAPHOTO-TMD300, Nikon, Tokyo, Japan). More than 1,000 red blood cells (RBCs) were counted in each mouse to assess parasitemia. On day 7 after infection, the permeability of the blood-brain barrier (BBB) was evaluated by Evans blue staining as follows: $0.1 \mathrm{~mL}$ of $2 \%(\mathrm{w} / \mathrm{v})$ Evans blue (056-04061; FUJIFILM Wako Pure Chemical Corporation, Osaka, Japan) dissolved 
in PBS was injected into infected mice with or without treatment with a-TEA through the tail vein. Two hours after injection the mice were sacrificed, and brain samples were collected.

Survival rates were analyzed using log-rank (Mantel-Cox) and Gehan-Breslow-Wilcoxon tests implemented in GraphPad Prism 5. Parasitemia was analyzed using a one-way analysis of variance and Tukey's test. A value of $P<0.05$ was considered statistically significant.

Experimental in vitro infections with $P$. falciparum 3D7 and $\mathrm{K} 1$ were performed using human $\mathrm{O}+\mathrm{RBCs}$ (Japanese Red Cross Society, Hokkaido, Japan). Both parasites were maintained in complete Roswell Park Memorial Institute-1640 medium (RPMI-1640, Sigma-Aldrich, MO, USA), containing, per liter, $6 \mathrm{~g}$ HEPES (Sigma-Aldrich, MO, USA), 25 mg hypoxanthine (Wako, Osaka, Japan), $2 \mathrm{~g} \mathrm{NaHCO}_{3}$ (Wako, Osaka, Japan), $250 \mu \mathrm{L}$ of $50 \mathrm{mg} / \mathrm{ml}$ gentamicin solution (Gibco, CA, USA), and $5 \mathrm{~g}$ AlbuMax ${ }^{\mathrm{TM}}$ II Lipid-Rich BSA (Gibco, CA, USA). The medium was changed daily and parasitemia was monitored using Giemsa-stained thin blood smears (Merck, Darmstadt, Germany). Malarial parasite culture in human blood was approved by the ethical committee of Obihiro University of Agriculture and Veterinary Medicine (\#2013-04-3).

In vitro growth inhibition of $P$. falciparum 3D7 and K1 was performed using the SYBR Green l-based fluorescence assay (SYBR® Green I Nucleic Acid Stain 10,000x, ME, USA) as previously described [28, 29]. Briefly, test compounds were prepared in complete media at eight final concentrations (two-fold serial dilution) ranging from 100 to $0.78 \mu \mathrm{M}$. Chloroquine diphosphate (molecular weight $515.86 \mathrm{~g} / \mathrm{mol}$; SigmaAldrich, MO, USA) was used as the reference drug. Before use, the parasites' life cycle was synchronized by treatment with $5 \% \mathrm{D}$-sorbitol to obtain $\geq 90 \%$ ring-stage parasites. Synchronous parasites $(50 \mu \mathrm{L})$ at $0.5 \%$ parasitemia and $2 \%$ hematocrit were seeded in a 96 -well plate containing $50 \mu \mathrm{L}$ of the test compounds. The 96 -well plates were incubated for $72 \mathrm{~h}$ at $37^{\circ} \mathrm{C}$ in $5 \% \mathrm{CO}_{2}, 5 \% \mathrm{O}_{2}$, and $90 \% \mathrm{~N}_{2}$. Next, 100 $\mu \mathrm{L}$ of lysis buffer containing $1 \times$ SYBR Green I was added to each well, mixed by pipetting, and then incubated in the dark at room temperature for $2 \mathrm{~h}$. Fluorescence intensities were measured using a Fluoroskan Ascent instrument (Thermo Scientific, MA, USA) at excitation and emission wavelengths of 485 and $518 \mathrm{~nm}$, respectively. Cells treated with 1\% (v/v) DMSO were used as a negative control, and wells containing only test compounds and erythrocytes were used to correct the background signals. The inhibition assays were performed in quadruplicate for each concentration and repeated three independent times. The half-maximal inhibitory concentration $\left(\mathrm{IC}_{50}\right)$ values were analyzed using nonlinear regression analysis implemented in GraphPad Prism 8.

Human foreskin fibroblast cells (HFFs) were maintained in Dulbecco's modified Eagle's medium (DMEM, Sigma-Aldrich, MO, USA) supplemented with $10 \%$ fetal bovine serum (FBS) and $1 \%$ penicillinstreptomycin solution ( $\times 100$, Wako, Osaka, Japan) at $37^{\circ} \mathrm{C}$ and $5 \% \mathrm{CO}_{2}$ in air. A cell viability assay was used to evaluate the cytotoxic effects of the tested compounds, as previously described [28]. Briefly, the cell suspension was seeded in a 96-well plate at a density of $1 \times 10^{4}$ cells/well in DMEM with $10 \%$ FBS and incubated for $48 \mathrm{~h}$ at $37^{\circ} \mathrm{C}$ and $5 \% \mathrm{CO}_{2}$ in air. Then, two-fold dilutions (total eight concentrations) of the test compounds in DMEM were added in quadruplicate to each well and incubated for an additional $72 \mathrm{~h}$. Cell Counting Kit-8 (CCK-8) was added and incubated for an additional $3 \mathrm{~h}$ at $37^{\circ} \mathrm{C}$ and $5 \% \mathrm{CO}_{2}$ in 
air, and the absorbance was measured at $450 \mathrm{~nm}$. The tests were independently repeated three times. The half-maximal cytotoxic concentration $\left(\mathrm{CC}_{50}\right)$ values were analyzed using nonlinear regression analysis implemented in GraphPad Prism 8.

The human RBC hemolysis assay was performed as previously described [30]. Briefly, each test compound was prepared in $1 \times$ phosphate-buffered saline (PBS) at a desired concentration in a 96-well plate, and $3 \%$ RBCs suspension in PBS was added. The plate was incubated for $3 \mathrm{~h}$ at $37^{\circ} \mathrm{C}$ in $5 \% \mathrm{CO}_{2}, 5 \%$ $\mathrm{O}_{2}$, and $90 \% \mathrm{~N}_{2}$ and then centrifuged at 1,300 $\times \mathrm{g}$ for $5 \mathrm{~min}$. Finally, $100 \mu \mathrm{L}$ of the supernatant of each mixture was transferred to a new 96-well plate, and the absorbance was recorded at $540 \mathrm{~nm}$. PBS (with $1 \%$ DMSO) and $\mathrm{RBC}$ lysis buffer $\left(0.83 \% \mathrm{NH}_{4} \mathrm{Cl} ; 0.01 \mathrm{M} \mathrm{Tris-HCl}, \mathrm{pH} 7.2\right)$ were used as negative and positive controls, respectively. The hemolysis rate of RBCs was calculated using the following formula: Hemolysisrate $=\left[\left(\mathrm{A}_{\text {sample }}-\mathrm{A}_{\text {negative control }}\right) /\left(\mathrm{A}_{\text {positive control }}-\mathrm{A}_{\text {negative control }}\right) \times 100\right]$, where $\mathrm{A}$ stands for absorbance. The experiments were performed in technical quadruplicates, and independently repeated three times.

\section{Results}

As shown in Figure 1A, the effect of the administration of a-TEA on P. berghei ANKA infected mice was remarkable. Although the parasitemia of $0.75 \%$ a-TEA treated mice was found to be significantly lower than that of the untreated group on day 10 after infection (Figure 1B), both control and $0.75 \% \mathrm{a}$-TEAtreated mice died within 12 days after infection (Figure 1A). Remarkably, when 1.5\% a-TEA was mixed with the diet for the 14 days following infection, $88 \%$ of the P. berghei ANKA-infected mice survived the experimental period. In fact, the proportion of parasitemia in this group of mice was significantly lower than that of the control group on days 4,8 , and 10 following infection $(P<0.05)$. Seven days after infection, Evans blue staining was observed to be maximal in the mice from the untreated group, while staining intensity was dramatically attenuated by 0.75 and $1.5 \%$ a-TEA treatment (Figure 2 ).

The in vitro effects of a-TEA are summarized in Tables 1 and 2 and are shown in Figure 3. The proliferation of $P$. falciparum was inhibited by a-TEA in both 3D7 $\left(\mathrm{IC}_{50} 13.89 \pm 1.16 \mu \mathrm{M}\right)$ and $\mathrm{K} 1\left(\mathrm{IC}_{50}\right.$ $15.51 \pm 0.56 \mu \mathrm{M})$ strains. The cytotoxicity of a-TEA against human foreskin fibroblast (HFF) cells showed the cytotoxic concentration $\mathrm{CC}_{50}$ value of $80.41 \pm 17.24 \mu \mathrm{M}$, resulting in the selectivity indexes $(\mathrm{SI})$ of 5.79 and 5.18 for $P$. falciparum 3D7 and K1, respectively. Furthermore, at a concentration of $100 \mu \mathrm{M}, \mathrm{a}-$ TEA exhibited an RBC hemolysis rate of $14.70 \pm 1.12 \%$. 
Table 1

In vitro examinations of a-TEA and chloroquine against $P$. falciparum, HFF cells, and RBC hemolysis rate*

\begin{tabular}{|c|c|c|c|c|c|c|}
\hline \multirow[t]{2}{*}{ Compound } & \multicolumn{2}{|c|}{$\begin{array}{l}\mathrm{IC}_{50} P . \text { falciparum } \\
(\mu \mathrm{M})\end{array}$} & \multirow[t]{2}{*}{$\begin{array}{l}\mathrm{CC}_{50} \text { HFF } \\
\text { Cells }(\mu \mathrm{M})\end{array}$} & \multicolumn{2}{|l|}{ SI } & \multirow[t]{2}{*}{$\begin{array}{l}\text { RBCs Hemolysis Rate } \\
\text { (\%) at } 100 \mu \mathrm{M}\end{array}$} \\
\hline & 3D7 & K1 & & 3D7 & $\mathrm{K} 1$ & \\
\hline $\mathrm{a}-\mathrm{TEA}$ & $\begin{array}{l}13.89 \pm \\
1.16\end{array}$ & $\begin{array}{l}15.51 \pm \\
0.56\end{array}$ & $80.41 \pm 17.24$ & 5.79 & 5.18 & $14.70 \pm 1.12$ \\
\hline Chloroquine & $\begin{array}{l}0.027 \pm \\
0.002\end{array}$ & $\begin{array}{l}0.740 \pm \\
0.055\end{array}$ & $26.69 \pm 6.58$ & 988.52 & 36.07 & $0.71 \pm 0.35$ \\
\hline
\end{tabular}

Table 2

The RBCs hemolysis rate of a-TEA at various concentrations*

\begin{tabular}{|lllllllll}
$\begin{array}{l}\text { Concentration } \\
(\mu \mathrm{M})\end{array}$ & $\mathbf{4 0 0}$ & $\mathbf{2 0 0}$ & $\mathbf{1 0 0}$ & $\mathbf{5 0}$ & $\mathbf{2 5}$ & $\mathbf{1 2 . 5}$ & $\mathbf{6 . 2 5}$ & $\mathbf{3 . 1 2 5}$ \\
$\begin{array}{l}\text { Hemolysis } \\
\text { Rate }(\%)\end{array}$ & $55.23 \pm$ & $24.09 \pm$ & $14.70 \pm$ & $5.76 \pm$ & $2.15 \pm$ & $0.75 \pm$ & $0.19 \pm$ & $0.20 \pm$ \\
\hline
\end{tabular}

* Values were mean \pm SD from three independent experiments.

\section{Discussion}

This study reports a significant effect for a-tocopheryloxy acetic acid (a-TEA) on the treatment of infection by $P$. berghei ANKA in mice. To date, a-TEA has been studied mainly for its antitumor effect [2126,31 , but the results of this study showed an anti-protozoal effect for this compound on $P$. yoelii $17 \mathrm{XL}$ infection in mice [18]. When a-TEA was mixed with the diet and orally administered to $P$. yoelii 17XLinfected mice, their survival was almost completely maintained and the parasites were eradicated from their blood cells [18]. In P. berghei ANKA-infected mice, a lower dosage of a-TEA (0.75\%) showed similar kinetics to control mice in both survival rate and parasitemia (Figure 1). However, when the infected mice were treated with a higher dose of a-TEA (1.5\%) for 14 days after infection, their survival was significantly higher and parasitemia was significantly lower than those in the control and $0.75 \%$ a-TEA-treated groups (Figure 1). This data suggests that it may be possible to maintain low levels of parasitemia by increasing the a-TEA concentration in the blood stream immediately before the elevation of parasitemia after the moment of infection. It has been reported that treatment with $50 \mathrm{mM}$ a-TOS after $P$. berghei ANKA infection significantly increased host survival in mice [16]. The median survival time of the solvent- and $50 \mathrm{mM}$ a-TOS-treated mice infected with P. berghei ANKA was 8.0 and 11.5 days after infection, respectively [16]. The effect of a-TEA on $P$. berghei ANKA infection was greater than that of a-TOS. In our study, approximately $90 \%$ of the infected mice treated with of $1.5 \%$ a-TEA survived throughout the experimental period (Figure 1A). As a-TEA is not hydrolyzed and has good stability [19, 20], it may be a candidate anti-malarial drug. In the pharmacokinetic experiment, in which a $0.25 \%$ a-TEA-mixed diet was 
fed to C57BL/6J mice for three weeks, the average food intake of the mice was $3.6 \mathrm{~g} / \mathrm{head} / \mathrm{day}$. The daily food intake was comparable to that of mice fed a normal chow diet. Based on this value, the mean $a-T E A$ intake was $9 \mathrm{mg} / \mathrm{head} /$ day. After a single oral dose of a-TEA (10 mg/head) administered to mice, the elimination half-life $\left(T_{1 / 2}\right)$ in plasma was $61.3 \mathrm{~h}$; the maximum concentration $\left(C_{\text {max }}\right)$ was $25.7 \mu \mathrm{g} / \mathrm{mL}$ and the area under the plasma concentration-time curve (AUC) was $1,780 \mu \mathrm{g} \cdot \mathrm{h} / \mathrm{mL}$. Furthermore, in mice for which $10 \mathrm{mg} /$ day a-TEA was orally administered for three days, the plasma a-TEA concentration was higher than $10 \mu \mathrm{g} / \mathrm{mL}$ for six days after the start of treatment [18].

To investigate if the antiprotozoal effect of a-TEA was the result of modifying the host physiology or a direct impact on the protozoan, the effect of a-TEA on the in vitro growth of $P$. falciparum was examined. The resulting $\mathrm{IC}_{50}$ values against 3D7 $(13.89 \pm 1.16 \mu \mathrm{M})$ and $\mathrm{K} 1(15.51 \pm 0.56 \mu \mathrm{M})$ strains' infection were close to those previously reported for plasma a-TEA concentration $(10 \mu \mathrm{g} / \mathrm{ml}$, which is equal to $20.46 \mu \mathrm{M})$ on the mice orally administered with $10 \mathrm{mg} /$ day for 3 days [18], indicating that a-TEA was affecting the parasite proliferation in mice. Notably, from the HFF cytotoxicity data, an in vitro a-TEA concentration below $25 \mu \mathrm{M}$ (Table 2) was considered to be safe, showing a $2.15 \%$ hemolysis rate, as recommended by the American Society for Clinical Pathology [32].

Collectively, our results indicate that the antimalarial effect of a-TEA was caused by its direct impact on parasites (Table 1 and Figure 3). Parasites may consume a-TEA from plasma and erythrocyte membranes. Similarly, in preliminary experiments, the in vitro proliferation of trypanosomes after a-TEA treatment was significantly inhibited compared with that after control treatment (no a-TEA), suggesting that a-TEA has a direct effect on trypanosomes. In addition, a-TEA induces the production of ROS, such as hydroxyl radicals and peroxynitrite, in protozoans [33]. Oxidative stress may inhibit parasite growth. We hypothesize that parasites exposed to a-TEA accumulate ROS by interference of this molecule with the mitochondrial redox chain and by stimulation of the intrinsic apoptotic pathway. Endothelial cells lacking mitochondrial DNA are resistant to $\mathrm{a}-\mathrm{TEA}$, both in the accumulation of ROS, induction of apoptosis, and maintenance of their angiogenic potential [34]. Furthermore, a-TEA has been shown to be a potent anti-cancer agent with a safe toxicity profile in mice [35] and dogs [36].

\section{Conclusion}

This study showed that a-TEA is effective against murine and human malaria in vivo and in vitro, respectively. Although a-TEA alone has a sufficient antimalarial effect, future research could focus on the combined effect of a-TEA and already existing drugs. The prophylactic antimalarial activity of premedication with a-TEA may also be an interesting perspective in the future.

\section{Declarations}

Consent for publication: Not applicable.

Funding: A part of this work was supported by grant from the Naito Foundation. 
Conflicts of interest: On behalf of all authors, the corresponding author states that there is no conflict of interest.

Ethics approval: The animals used in this study were treated and cared for based on the Guiding Principles for the Care and Use of Research Animals established by Obihiro University of Agriculture and Veterinary Medicine. All animal experimental protocols were approved by the Institutional Animal Ethics Committee, Obihiro University of Agriculture and Veterinary Medicine.

Availability of data and material: The data that support the findings of this study are available from the corresponding author upon reasonable request.

Authors' contributions: The research was designed by H.S., A.K., Y.N., and S.K. Laboratory experiments were performed by N.A. and A.K The manuscript was written by H.S., T.T., Y.N. and R.U-S. All the authors have read and agreed to the published version of the manuscript.

Acknowledgments: We would like to thank Editage (www.editage.com) for English language editing.

\section{References}

1. Friedman MJ. Oxidant damage mediates variant red cell resistance to malaria. Nature. 1979;280:245-7. DOI:10.1038/280245a0.

2. Clark IA, Hunt NH. Evidence for reactive oxygen intermediates causing hemolysis and parasite death in malaria. Infect Immun. 1983;39:1-6. DOI:10.1128/iai.39.1.1-6.1983.

3. Kline K, Yu W, Sanders BG.. . ; Supplement. Vitamin E and breast cancer. J Nutr. 2004;134:3458S62S. DOI:10.1093/jn/134.12.3458S.

4. Neuzil J, Dong LF, Ramanathapuram L, Hahn T, Chladova M, Wang XF, et al. Vitamin E analogues as a novel group of mitocans: anti-cancer agents that act by targeting mitochondria. Mol Aspects Med. 2007;28:607-45. DOI:10.1016/j.mam.2007.02.003.

5. Wang XF, Witting PK, Salvatore BA, Neuzil J. Vitamin E analogs trigger apoptosis in HER2/erbB2overexpressing breast cancer cells by signaling via the mitochondrial pathway. Biochem Biophys Res Commun. 2005;326:282-9. DOI:10.1016/j.bbrc.2004.11.028.

6. Wang XF, Birringer M, Dong LF, Veprek P, Low P, Swettenham E, et al. A peptide conjugate of vitamin $E$ succinate targets breast cancer cells with high erbB2 Expression. Cancer Res. 2007;67:3337-44.

DOI:10.1158/0008-5472.CAN-06-2480.

7. Qian M, Sanders BG, Kline K. RRR-alpha-tocopheryl succinate induces apoptosis in avian retrovirustransformed lymphoid cells. Nutr Cancer. 1996;25:9-26. DOI:10.1080/01635589609514424.

8. Neuzil J, Weber T, Schröder A, Lu M, Ostermann G, Gellert N, et al. Induction of cancer cell apoptosis by alpha-tocopheryl succinate: molecular pathways and structural requirements. FASEB J. 2001;15:403-15. DOI:10.1096/fj.00-0251com. 
9. Weber T, Lu M, Andera L, Lahm H, Gellert N, Fariss MW, et al. Vitamin E succinate is a potent novel antineoplastic agent with high selectivity and cooperativity with tumor necrosis factor-related apoptosis-inducing ligand (apo2 ligand) in vivo. Clin Cancer Res. 2002;8:863-9.

10. Weber T, Dalen H, Andera L, Nègre-Salvayre A, Augé N, Sticha M, et al. Mitochondria play a central role in apoptosis induced by alpha-tocopheryl succinate, an agent with antineoplastic activity: comparison with receptor-mediated pro-apoptotic signaling. Biochemistry. 2003;42:4277-91. DOI:10.1021/bi020527j.

11. Dong LF, Low P, Dyason JC, Wang XF, Prochazka L, Witting PK, et al. Alpha-tocopheryl succinate induces apoptosis by targeting ubiquinone-binding sites in mitochondrial respiratory complex II. Oncogene. 2008;27:4324-35. DOI:10.1038/onc.2008.69.

12. Dong LF, Freeman R, Liu J, Zobalova R, Marin-Hernandez A, Stantic M, et al. Suppression of tumor growth in vivo by the mitocan alpha-tocopheryl succinate requires respiratory complex II. Clin Cancer Res. 2009;15:1593-600. DOI:10.1158/1078-0432.CCR-08-2439.

13. Bellezza I, Grottelli S, Gatticchi L, Mierla AL, Minelli A. a-Tocopheryl succinate pre-treatment attenuates quinone toxicity in prostate cancer PC3 cells. Gene. 2014;539:1-7.

DOI:10.1016/j.gene.2014.02.009.

14. Yan B, Stantic M, Zobalova R, Bezawork-Geleta A, Stapelberg M, Stursa J, et al. Mitochondrially targeted vitamin E succinate efficiently kills breast tumour-initiating cells in a complex II-dependent manner. BMC Cancer. 2015;15:401. DOI:10.1186/s12885-015-1394-7.

15. Neuzil J. Alpha-tocopheryl succinate epitomizes a compound with a shift in biological activity due to pro-vitamin-to-vitamin conversion. Biochem Biophys Res Commun. 2002;293:1309-13.

DOI:10.1016/S0006-291X(02)00358-3.

16. Kume A, Kasai S, Furuya H, Suzuki H. a-Tocopheryl succinate-suppressed development of cerebral malaria in mice. Parasitol Res. 2018;117:3177-82. DOI:10.1007/s00436-018-6016-2.

17. Dong LF, Grant G, Massa H, Zobalova R, Akporiaye E, Neuzil J. a-Tocopheryloxyacetic acid is superior to a-tocopheryl succinate in suppressing HER2-high breast carcinomas due to its higher stability. Int J Cancer. 2012;131:1052-8. DOI:10.1002/ijc.26489.

18. Kawamura K, Kume A, Umemiya-Shirafuji R, Kasai S, Suzuki H. Effect of a-tocopheryloxy acetic acid, a vitamin E derivative mitocan, on the experimental infection of mice with Plasmodium yoelii. Malar J. 2021;20:280. DOI:10.1186/s12936-021-03817-9.

19. Lawson KA, Anderson K, Menchaca M, Atkinson J, Sun L, Knight V, et al. Novel vitamin E analogue decreases syngeneic mouse mammary tumor burden and reduces lung metastasis. Mo Cancer Ther. 2003;2:437-44.

20. Hahn T, Szabo L, Gold M, Ramanathapuram L, Hurley LH, Akporiaye ET. Dietary administration of the proapoptotic vitamin $\mathrm{E}$ analogue a-tocopheryloxyacetic acid inhibits metastatic murine breast cancer. Cancer Res. 2006;66:9374-8. DOI:10.1158/0008-5472.CAN-06-2403.

21. Jia L, Yu W, Wang P, Sanders BG, Kline K. In vivo and in vitro studies of anticancer actions of alphaTEA for human prostate cancer cells. Prostate. 2008;68:849-60. DOI:10.1002/pros.20750. 
22. Li Y, Hahn T, Garrison K, Cui ZH, Thorburn A, Thorburn J, et al. The vitamin E analogue a-TEA stimulates tumor autophagy and enhances antigen cross-presentation. Cancer Res. 2012;72:353545. DOI:10.1158/0008-5472.CAN-11-3103.

23. Yao J, Gao P, Xu Y, Li Z. a-TEA inhibits the growth and motility of human colon cancer cells via targeting RhoA/ROCK signaling. Mol Med Rep. 2016;14:2534-40. DOI:10.3892/mmr.2016.5525.

24. Yu W, Tiwary R, Li J, Park SK, Jia L, Xiong A, et al. a-TEA induces apoptosis of human breast cancer cells via activation of TRAIL/DR5 death receptor pathway. Mol Carcinog. 2010;49:964-73. DOI:10.1002/mc.20681.

25. Hahn T, Bradley-Dunlop DJ, Hurley LH, Von-Hoff D, Gately S, Mary DL, et al. The vitamin E analog, alpha-tocopheryloxyacetic acid enhances the anti-tumor activity of trastuzumab against HER2/neuexpressing breast cancer. BMC Cancer. 2011;11:471. DOI:10.1186/1471-2407-11-471.

26. Hahn T, Jagadish B, Mash EA, Garrison K, Akporiaye ET. a-Tocopheryloxyacetic acid: a novel chemotherapeutic that stimulates the antitumor immune response. Breast Cancer Res. 2011;13:R4. DOI: $10.1186 / \mathrm{bcr} 2808$.

27. Rodríguez-Enríquez S, Hernández-Esquivel L, Marín-Hernández A, Dong LF, Akporiaye ET, Neuzil J, et al. Molecular mechanism for the selective impairment of cancer mitochondrial function by a mitochondrially targeted vitamin E analogue. Biochim Biophys Acta. 2012;1817:1597-607. DOI:10.1016/j.bbabio.2012.05.005.

28. Leesombun A, lijima M, Pagmadulam B, Orkhon B, Doi H, Issiki K, et al. Metacytofilin has potent antimalarial activity. Parasitol Int. 2021;81:102267. DOI:10.1016/j.parint.2020.102267.

29. Smilkstein M, Sriwilaijaroen N, Kelly JX, Wilairat P, Riscoe M. Simple and inexpensive fluorescencebased technique for high-throughput antimalarial drug screening. Antimicrob Agents Chemother. 2004;48:1803-6. DOI:10.1128/AAC.48.5.1803-1806.2004.

30. Evans BC, Nelson CE, Yu SS, Beavers KR, Kim AJ, Li H, et al. Ex vivo red blood cell hemolysis assay for the evaluation of $\mathrm{pH}$-responsive endosomolytic agents for cytosolic delivery of biomacromolecular drugs. J Vis Exp. 2013;73:e50166. DOI:10.3791/50166.

31. Hahn T, Akporiaye ET. a-TEA as a stimulator of tumor autophagy and enhancer of antigen crosspresentation. Autophagy. 2013;9:429-31. DOI:10.4161/auto.22969.

32. Goyal T, Schmotzer CL. Validation of hemolysis index thresholds optimizes detection of clinically significant hemolysis. Am J Clin Pathol. 2015;143:579-83. DOI:10.1309/AJCPDUDE1HRAOYMR.

33. Kawamura K, Suzuki H. 2022, Unpublished work.

34. Dong LF, Swettenham E, Eliasson J, Wang XF, Gold M, Medunic Y, et al. Vitamin E analogues inhibit angiogenesis by selective induction of apoptosis in proliferating endothelial cells: the role of oxidative stress. Cancer Res. 2007;67:11906-13. DOI:10.1158/0008-5472.CAN-07-3034.

35. Hahn T, Akporiaye ET. Repeat dose study of the novel proapoptotic chemotherapeutic agent alphatocopheryloxy acetic acid in mice. Anti Cancer Drugs. 2012;23:455-64.

DOI:10.1097/CAD.0b013e32834f6271. 
36. Guerrouahen BS, Hahn T, Alderman Z, Curti B, Urba W, Akporiaye ET. GMP-grade a-TEA lysine salt: a 28-day oral toxicity and toxicokinetic study with a 28-day recovery period in beagle dogs. BMC Cancer. 2016;16:199. DOI:10.1186/s12885-016-2220-6.

\section{Figures}

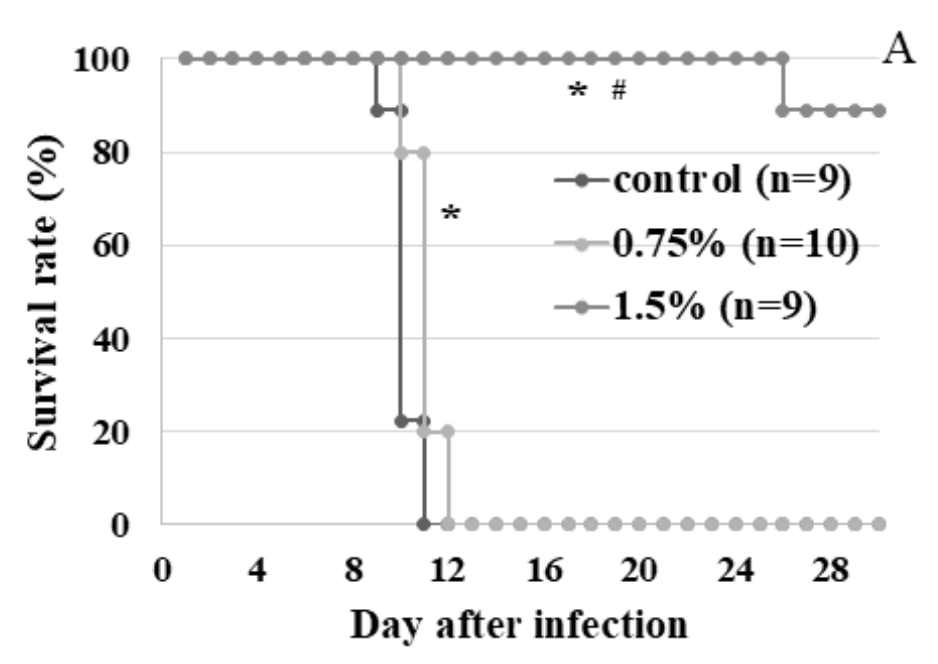

Day after infection

A

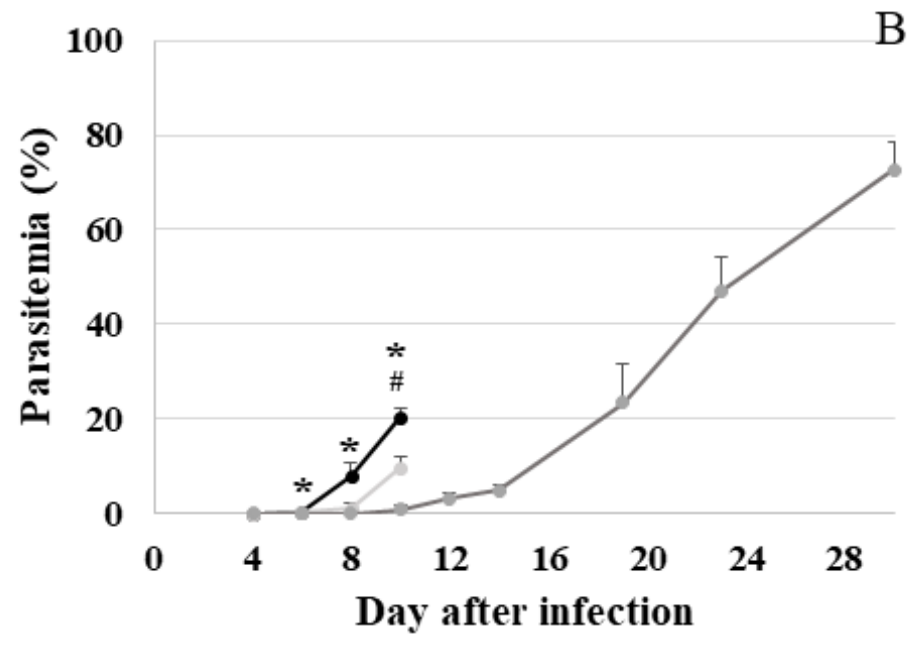

Fig. 1

\section{Figure 1}

Effect of a-TEA mixed with diet on mice survival (A) and parasitemia (B) following $P$. berghei ANKA infection. A concentration of $0.75 \%$ and $1.5 \%(\mathrm{w} / \mathrm{w})$ a-TEA was mixed with diet and fed to C57BL/6J mice for 14 days after infection with $4 \times 10^{4} P$. berghei ANKA infected red blood cells (RBCs.) Error bars indicate standard error. An * indicates $\mathrm{P}<0.05$ on $1.5 \%(\mathrm{w} / \mathrm{w})$ a-TEA vs untreated group; $A$ \# indicates $\mathrm{P}<$ 0.05 on $1.5 \%(w / w)$ vs $0.75 \%(v / v)$ a-TEA group. 


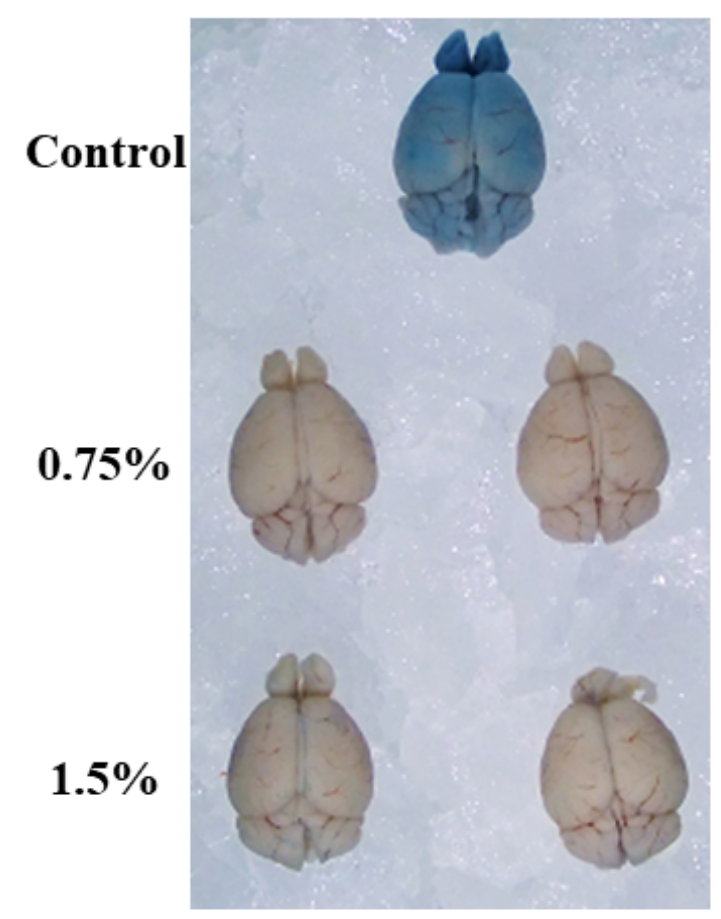

Fig. 2

\section{Figure 2}

Permeability of blood-brain barrier (BBB) in mice infected with $P$. berghei ANKA assessed by Evans blue staining. Evans blue solution was injected to infected mice through tail vein on day 7 following infection. After $2 \mathrm{~h}$ following injection, mice were sacrificed and dissected. Brains were taken from untreated mice infected with P. berghei ANKA (control; upper panel) and from $0.75 \%$ and $1.5 \%$ (w/w) a-TEA-treated mice infected with $P$. berghei ANKA (middle and lower panels, respectively). 
A

P. falciparum 3D7

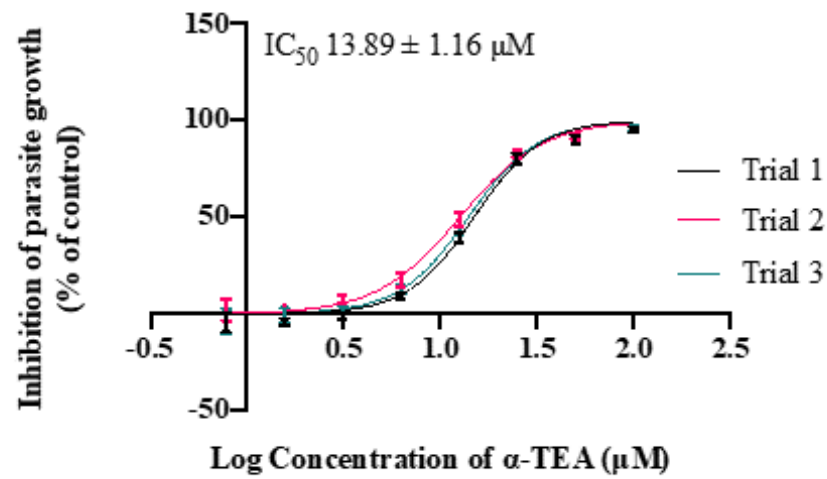

$\mathrm{C}$

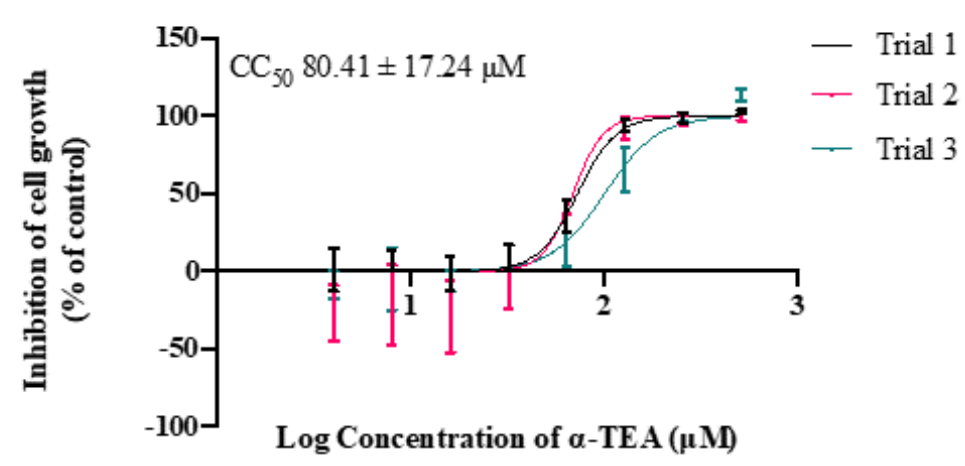

Fig. 3
B

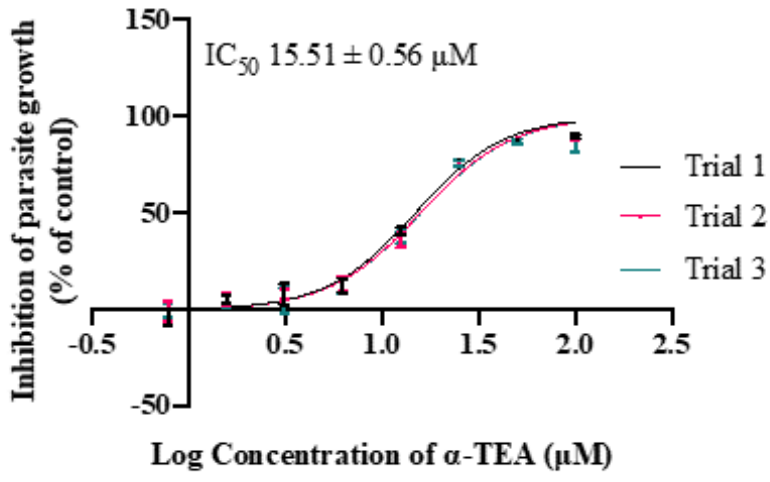

$\mathrm{D}$

\section{Human RBCs}

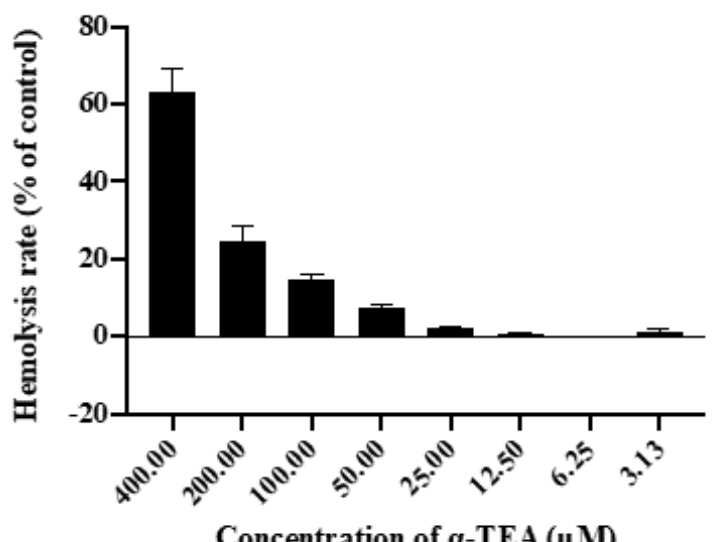

Figure 3

In vitro effect of different concentrations of a-TEA against Plasmodium falciparum 3D7 (A), P. falciparum $\mathrm{K} 1$ (B), and human foreskin fibroblast (HFF) cells (C) at $72 \mathrm{~h}$ culture. In each graph, three curves are represented, indicating three independent trials. The bar graph shows the representative hemolysis rate of human red blood cells (RBCs) (D). Each data point (A-C) is the mean of four technical replicates, and error bars indicate the standard deviations. 